\title{
Extended endoscopic frontal nasal sinus surgery in management of chronic and recurrent frontal sinus diseases
}

\author{
Ahmed Sobhi Abdelaal ${ }^{1 *}$, Mohamed Kamel Al Awady ${ }^{1}$ and Tawfik Abdelaty Elkholy ${ }^{2}$
}

\begin{abstract}
Background: The anatomical variation of the frontal sinus and its intimate relation to the skull base and orbit makes its surgery demanding. The extended endoscopic frontal sinus surgery allows wide better drainage and preventing the recurrence of the disease. Fourteen patients underwent EEFSS from May 2017 to May 2019. These patients are nine patients presented by chronic recurrent frontal sinusitis, three patients presented by chronic recurrent fronto ethmoidal mucocele and two patients with chronic recurrent external frontal fistula. Draff III done for ten patients of them and Draff IIB done for four patients of them. This study is designed for evaluating the efficacy of the extended endoscopic frontal sinus surgery (E E F S S) in management of chronic and recurrent frontal sinus diseases.

Results: The neo opening of the restored frontal sinus was remained opened with Draff III with high success rate; two patients from four patients with Draff Ilb were with closed nasofrontal duct. The main follow-up was 12 months; the patients were followed up post-operatively for many office visits without any other manifestations.

Conclusion: The chronic recurrent frontal sinus diseases can be treated successfully with extended endoscopic frontal sinus surgery (E E F S S). The extended endoscopic frontal sinus surgery (Draff III) provides good results with low morbidity and less post-operative care.
\end{abstract}

Keywords: Endoscopic, Frontal sinus, Draff, Recurrent, Frontal sinusitis

\section{Background}

Chronic recurrent frontal sinusitis and other frontal sinus diseases are considered the main challenge for endoscopic sinus surgery [1]. There was early publication based on conservative functional approach [2], now the concept was based on the radical one [3]. Draff III procedure keeps a significance where it is combined with radical spheno ethmoidectomy [4].

In principle, the frontal sinus surgery can be done through endonasal approach and externally [5]. Recently, the endonasal approach has been established following the good understanding of sinus pathophysiology, optical

\footnotetext{
*Correspondence: dr_ahmedsobhi84@yahoo.com

'Otorhinolaryngology Department., Faculty of Medicine, Al Azhar University., Cairo, Egypt

Full list of author information is available at the end of the article
}

aids, and modern instrumentation [6]. With increasing in the surgical experience, elective trauma and tumor cases are managed successfully with endonasal approach [7].

With the advance of endoscope, computed tomography and drill technologies, widening the ostium of the frontal sinus with preservation of sinus mucosa becomes allowed and this advantage decreases the morbidity, improving the cosmoses and allowing the ability to evaluate the patient endoscopically post-operatively with shorter hospital stay, decreased pain and frontal and orbital edema, and these advantages occurred with Draff surgery [8].

The main endoscopic surgery in our study is Draff III which involves removal of the frontal bone beak and the joining of the two frontal sinus ostia making large neofrontal cavity. 
Table 1 The indications for EEFSS

\begin{tabular}{llll}
\hline & No. & $\%$ \\
\hline Diagnosis (indication) & $\begin{array}{l}\text { Chronic recurrent frontal } \\
\text { sinusitis }\end{array}$ & 9 & 64.3 \\
& $\begin{array}{l}\text { Chronic recurrent external } \\
\text { frontal fistula } \\
\text { Chronic recurrent fronto } \\
\text { ethmoidal mucocele }\end{array}$ & 2 & 14.3 \\
\hline
\end{tabular}

\section{Methods}

This is a prospective study done from May 2017 to May 2019 on fourteen patients to assess the efficacy of the extended endoscopic frontal sinus surgery on chronic recurrent frontal sinus diseases. These patients are nine patients presented by chronic recurrent frontal sinusitis, three patients presented by chronic recurrent fronto ethmoidal mucocele and two patients with chronic recurrent external frontal fistula. Draff III done for ten patients of them (eight patients with chronic recurrent frontal sinusitis, two patients with chronic recurrent external frontal fistula). Draff IIB done for four patients of them (one with chronic recurrent frontal sinusitis and three patients with chronic recurrent fronto ethmidal mucocele). All patients were assessed clinically and endoscopically, and CT scan was done for them pre- and post-operative. All fourteen patients underwent previous sinus surgery with an average two previous surgeries.

For all patients, written informed consent was done after explanation of the study.

\section{Inclusion criteria}

Patients with benign chronic recurrent diseases of the frontal sinus who had failed previous endoscopic frontal sinus surgery.

\section{Exclusion criteria}

Including patients with primary chronic diseases of the frontal sinus and malignant cases.

All patients suspected to full history, clinical assessment with anterior rhinoscopy, endoscopic examination of the nose with 0 and 45 sinuscope. All patients suspected to CT paranasal sinuses pre-operatively to diagnose any pathological and associated lesions and as routine guide for the operation.

Table 2 Comparison between Draff III and Draff IIB regarding the success rate

\begin{tabular}{lllllll}
\hline & & & Failed & Succeeded & $\boldsymbol{X}^{\mathbf{2}}$ & $\boldsymbol{P}$ value \\
\hline $\begin{array}{lllllll}\text { Type of operation } \\
\text { (mode of technique) }\end{array}$ & Draff IIB & No. & 2 & 2 & 2.715 & .099 \\
& & $\%$ & $50 \%$ & $50 \%$ & & \\
& Draff III & No. & 1 & 9 & & \\
& & $\%$ & $10 \%$ & $90 \%$ & & \\
\hline
\end{tabular}

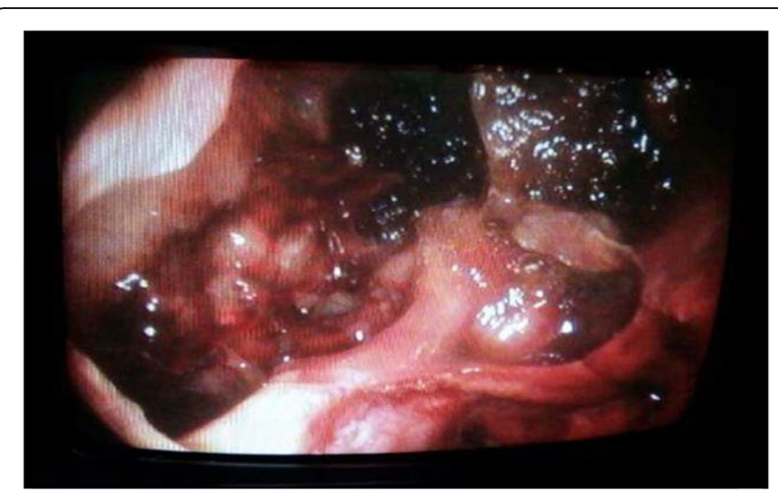

Fig. 1 Post-operative endoscopic view of Draff III, 1 week postoperative for patient who has external frontal fistula

Preparatory and anesthesiology measures were applied to minimize the bleeding during the endoscopic surgery to minimize the duration of the operation, to reduce the process of the wound healing, granulation tissue formation, and scaring post-operatively.

Topical vasoconstriction, e.g., by application of gauze soaked with diluted adrenalin with normal saline (concentration: 1:200,000).

Pre-operative preparation was done for all patients who admitted for surgery. Available instruments as endoscopic instruments are 0-, 45-, 70-degree endoscope, plexy up, thorough cutting up, frontal sinus probe, giraffe-type frontal cups, mushroom punch, and microdebriders which have different angles (40-, 60-, and 90-degree) which can be used with diamond and cutting bursaution under direct vision for selective removal of polyps, bony partitions.

\section{Surgical technique}

The patients were prepared in anti-Trendelenberg position and hypotensive anesthesia was done. An intraoperative endoscopic demonstration of the middle meatus, the osteomeatal complex, identification of axilla of middle turbinate, the uncinate process, lamina papyrcia, and agger nasi cells were identified. Uncinectomy, anterior ethmoidectomy, middle meatal antrostomy, trimming the anterior end of middle turbinate, agger-nasi cell was removed, frontal recess was identified, uncapping ostium of the frontal sinus with curette and through the frontal

Table 3 Post-operative endoscopic finding for the patients underwent EEFSS

\begin{tabular}{llll}
\hline & No. & $\%$ \\
\hline $\begin{array}{l}\text { Post-operative } \\
\text { endoscopic finding }\end{array}$ & $\begin{array}{l}\text { Obstructed (closed) } \\
\text { nasofrontal duct, } \\
\text { lateralized middle } \\
\text { turbinate, extensive } \\
\text { synechia, and neo-bone } \\
\text { formation }\end{array}$ & & \\
& Patent nasofrontal duct & 11 & 78.6 \\
\hline
\end{tabular}




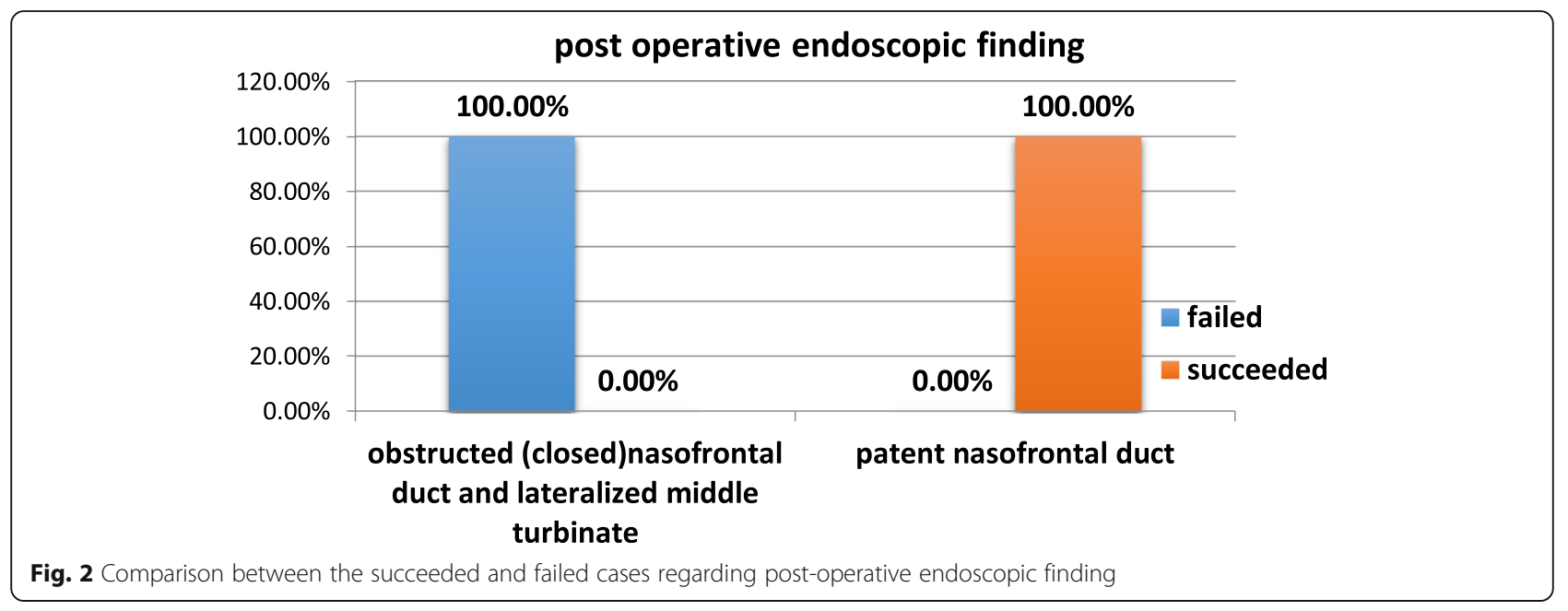

opening, the curved suction can pass through its anterior surface.

Dilatation of frontal sinus opening where the frontal sinus floor is removed with micro drill from the lamina papyrcia laterally till the septum medially (Draff type IIb). If the procedure is completed where the posterosuperior part of the septum and inter sinus septum were removed with opening and removal the floor of the contralateral frontal sinus as the first one from the septum medially till the other lamina papyrcia laterally with preservation of the mucosa as possible, it is (Draff type III). Avoidance of injury of the mucosa as possible and any bleeder of the septum and on the skull base are controlled with bipolar forceps and merocele nasal packing was inserted in the middle meatus. Post-operative nasal douching was done with alkaline nasal wash by the patient to avoid accumulation of granulation tissue, crusts and keeps the frontal sinus is opened and prevents the restenosis and continued till healing occurred. Systemic antibiotic was given for 1 week. Post-operative endoscopic assessment, 1 week to clean the operative field from any crust or synechia, 3, 6 months, and 1 year post-operative. Also, post-operative CT was done after 6 months.

\section{Main outcome measures}

All patients were assessed of the restoration of the communication of the frontal sinus by endoscopic assessment the patency of the nasofrontal duct after 1 week, 3 months, 6 months, and 1 year post-operative and by post-operative CT after 6 months.

\section{Statistical analysis}

The data were coded, entered, and processed on computer using Statistical package for social science (SPSS) (version 24). The results were represented in tabular and diagrammatic forms then interpreted. Mean, standard deviation, range, frequency, and percentage were used as descriptive statistics.

The following test was done:

- Chi-square test $X^{2}$ was used to test the association variables for categorical data.

- Student's $t$ test was used to assess the statistical significance of the difference between two population means in a study involving independent samples.

$P$ value was considered significant as the following:

" $P>0.05$ : non-significant.

* $P \leq 0.05$ : significant.

\section{Results}

The main age of patients was 14-61 years. The mean age was 37 years $(\mathrm{SD}=13.6$ years) with a male-to-female ratio of 3:1. The most common indication of our study is 9 patients with chronic refractory frontal sinusitis (64.3\%), 3 patients with chronic recurrent frontoethmoidal mucocele (21.4\%), and 2 patients with chronic recurrent external frontal fistula (14.3\%) (Table 1). Only one intra operative major complications was reported as orbital injury of the lamina papyrcia and penetration of orbital fat and the post-operative minor complications

Table 4 Post-operative CT finding for the patients that underwent EEFSS

\begin{tabular}{llll}
\hline & & No. & $\%$ \\
\hline Post-operative CT finding & Aerated of restored frontal sinus & 11 & 78.6 \\
& Opacification of restored frontal sinus and ethmoidal region & 3 & 21.4 \\
\hline
\end{tabular}




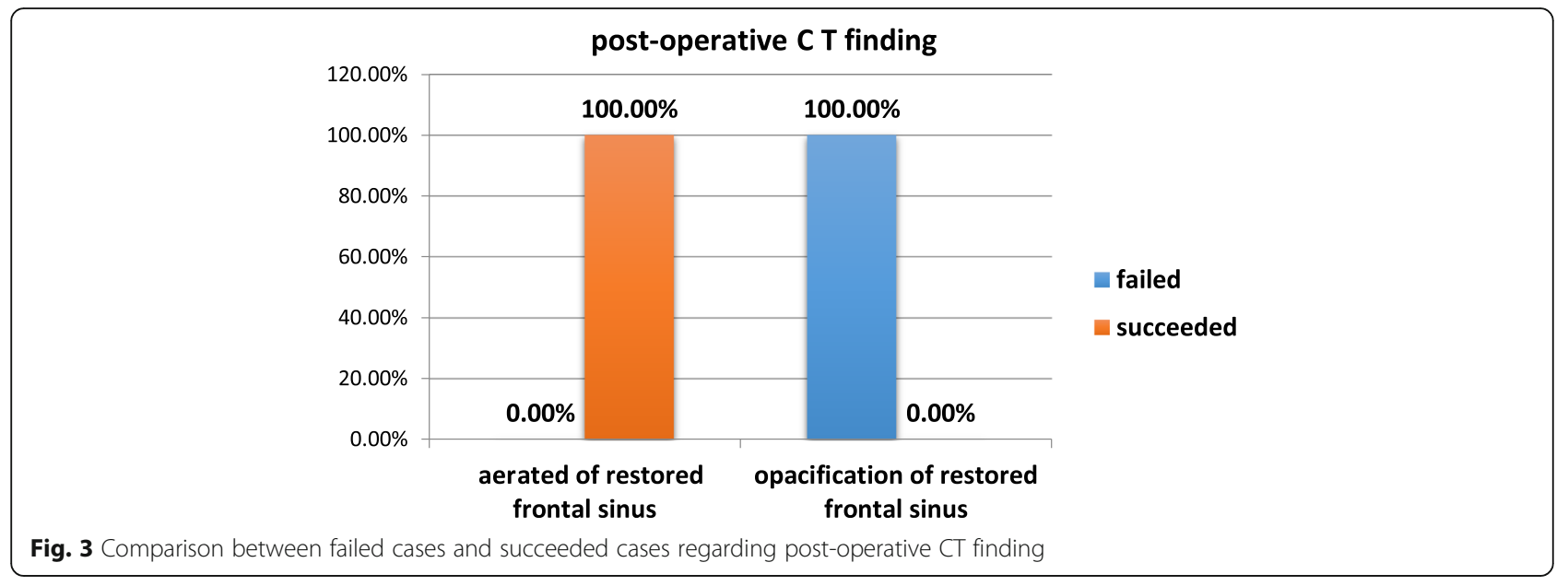

were $14.2 \%$ as post-operative adhesions, crust formation, epistaxis anosmia, and hyposmia.

Draff III done for ten patients and Draff IIB done for 4 patients from total 14 patients and the success rate for Draff III was $90 \%$ and for Draff IIB was 50\% (Table 2). The success rate is according to the post-operative endoscopic finding (patency of the restored naso-frontal duct) and the post-operative CT finding (aerated of the restored naso-frontal sinus).

The patients were followed up for 12 months, 1 week for removal of any granulation tissue, crusts by forceps, and suction assisted by endoscope in the ENT office, 3 months, 6 months, and 1 year for removal of any granulation tissue, crusts and release of mild to moderate synechia and sinuscopic assessment (Fig. 1).

The extensive synechia with lateralized middle turbinate and neo-bone formation with closed nasofrontal duct were seen in 3 patients, and patent nasofrontal duct were seen in 11 patients (Table 3).

All the 3 failed EEFSS (2 Draff IIB and 1 Draff III) had reported endoscopic finding as lateralized middle turbinate, extensive synechia, and neo-bone formation with obstruction of the nasofrontal duct. On the opposite side, the clear operative field and patent nasofrontal duct with all 11 succeeded cases (Fig. 2).
The percentage of post-operative endoscopic finding was statistically higher among failed cases than succeeded cases.

The percentage of post-operative endoscopic finding was statistically higher among failed cases than succeeded cases.

CT done for all patients at 6 months which reveals aerated patent restored frontal sinus in 11 patients and opacification of the restored frontal sinus and ethmoidal region in 3 patients (Table 4).

With follow-up, the patients and CT done at 6 months post-operative, we notice radiological changes as opacification of the restored frontal sinus and ethmoidal region in the 3 failed cases and aerated the restored frontal sinus in 11 succeeded (Fig. 3).

The percentage of post-operative CT finding was statistically lower among failed cases than succeeded cases.

There is only major intraoperative complication that occurred in one patient as injury of lamina papyrcia with penetration of orbital fat without any big sequelae affecting the vision or the orbital movement. The minor postoperative complications occurred in 2 patients as postoperative hyposmia, epistaxis, and crust. Extensive synachia and neo-bone formation occurred in 4 patients. There is no minor or major complication in 7 patients (Table 5).

The injury of lamina papyrcia passed without affecting the success of the surgery as happened in patient

Table 5 Intra and post-operative complications for the patients that underwent EEFSS

\begin{tabular}{llll}
\hline & & No. & $\%$ \\
\hline Intra and post-operative complications & No & 50.0 \\
& Orbital injury (penetration of orbital fat) (major intra operative complication) & 1 & 7.1 \\
& Post-operative crusts (minor) & 7.1 & 1 \\
& Post-operative extensive synechia with neo-bone formation (minor) & 4 & 28.6 \\
& Post-operative hyposmia and epistaxis (minor) & 7.1 \\
\hline
\end{tabular}


Table 6 Comparison between failed cases and succeeded cases regarding post-operative complications

\begin{tabular}{|c|c|c|c|c|c|c|}
\hline & & & Failed & Succeeded & $x^{2}$ & $P$ value \\
\hline \multirow[t]{10}{*}{ Intra and post-operative complications } & \multirow[t]{2}{*}{ No } & No. & 0 & 7 & 9.545 & 0.049 \\
\hline & & $\%$ & $.0 \%$ & $63.6 \%$ & & \\
\hline & \multirow{2}{*}{$\begin{array}{l}\text { Orbital injury with injury of lamina papyrcia and } \\
\text { penetration of orbital fat (major complication) }\end{array}$} & No. & 0 & 1 & & \\
\hline & & $\%$ & $.0 \%$ & $9.1 \%$ & & \\
\hline & \multirow[t]{2}{*}{ Post-operative crusts (minor) } & No. & 0 & 1 & & \\
\hline & & $\%$ & $.0 \%$ & $9.1 \%$ & & \\
\hline & \multirow{2}{*}{$\begin{array}{l}\text { Post-operative extensive synechia with neo-bone } \\
\text { formation }\end{array}$} & No. & 3 & 1 & & \\
\hline & & $\%$ & $100.0 \%$ & $9.1 \%$ & & \\
\hline & \multirow[t]{2}{*}{ Post-operative hyposmia and epistaxis (minor) } & & 0 & 1 & & \\
\hline & & & $.0 \%$ & $9.1 \%$ & & \\
\hline
\end{tabular}

underling Draff III (Fig. 4) . The extensive synechia and neo bone formation is responsible for obstruction the nasofrontal duct and failure of the surgery and post perative hyposmia and crust are self limiting as shown in (Table 6).

\section{Discussion}

The anatomical variation of the frontal sinus and its intimate relation to the skull base and orbit makes its surgery demanding. The endoscopic clearance of the recess of the frontal sinus is the first-line management for chronic frontal sinusitis. The main issue in frontal sinus surgery is muco-ciliary drainage, restoration, and aeration of it by removal the fronto-ethmodal air cell. The frontal recess, ostium, and sinus are the most common sites of recurrence [3]. Recent study shown that Draff III improves the quality of life [9].

Orlandi and Kennedy thought that the enlargement of agger-nasi cells and medial displacement of the uncinate process are the commonest 2 causes of frontal recess obstruction in patients without history of previous operation [10].
In our study, 4 patient developed new bone osteo genesis and frontal sinus stenosis developed. The failed procedures were 2 Draff III from ten Draff III operations and 2 Draff IIB from 4 Draff IIB. All patients were followed-up for 12 months. The frontal sinus remained opened for this period with adequate drainage. It was noted that the previous operations have very important role in recurrent frontal sinus diseases although the other sinuses (maxillary and ethmoid sinuses) contribute to nasal symptoms and frontal sinus diseases.

Intact frontal sinus mucosa of the frontal sinus is very important for avoiding scaring and obstruction of the ostium of the frontal sinus. Several studies reported that intact frontal sinus mucosa and image guidance have very important role, but understanding the anatomical outflow tract of the frontal sinus is very important for avoiding the complications [12].

The success rate increased with improvement of the facility of endoscopic sinus surgery and maintenance of the patency are assessed by endoscopic assessment in the post-operative visit.

In a study done on patients who underwent to Draff III by Samaha et al. with followed-up from 1.4-6.9 years,

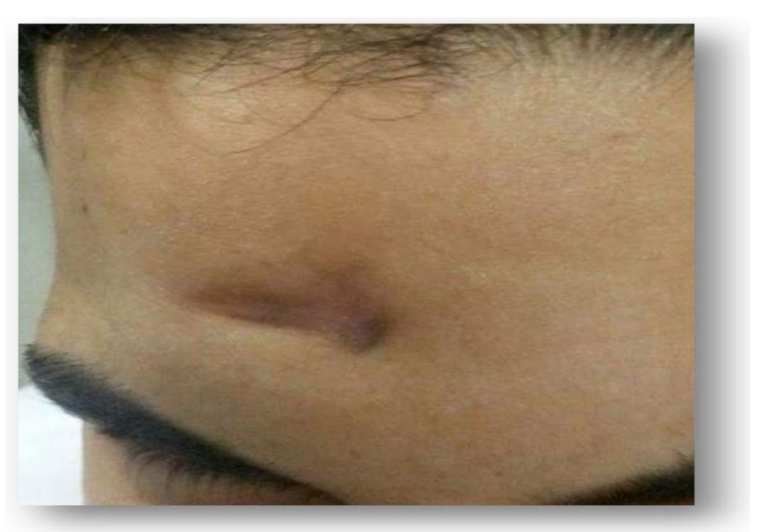

Fig. 4 Post-operative patient who had external frontal sinus opening which was closed after Draff III operation 
he noted that the patency of the neo-ostium of the frontal sinus was $80 \%$ and nine percent required a frontal sinus obliteration and eleven percent required endonasal revision surgery [7].

A similar study done by Schlosser et al. who did Draff III with average follow-up from 10-90 months, the patency of the neo-ostium of the frontal sinus after Draff III was $68 \%$ after one operation (the patient did one operation before Draff) and was $82 \%$ after 2 operations (the patient did two operations before Draff). The patency of the neo-ostium of the frontal sinus opened widely in $64 \%$ and closed in $23 \%$,but narrowed in $13 \%$ in this study $[12,11]$. In our study, the good-wide opening of the neo-nasofrontal ostium and wide drainage give patency rate of $90 \%$ in Draff III and 50\% for Draff IIB (after at least 2 previous endoscopic sinus surgery) and follow-up for 12 months. The added benefits of our technique are as follows: no donor site morbidity, no external incision (no scar), an increase in the patient comfort and compliance, and less operative time. There are limitations of our study including the need for large number of patients, absence of control group, and no use of external approach.

\section{Conclusion}

The extended endoscopic frontal sinus surgery is done in this study with good results where Draff III provides overall patency $90 \%$ which gives better results than Draff IIB.

\section{Abbreviations \\ E E F S S: Extended endoscopic frontal sinus surgery; EMLP: Endoscopic modified lothtrop procedure; CT: Computerized tomography}

\section{Acknowledgements}

Not applicable

\section{Authors' contributions}

Dr. MK diagnose and investigate the patients with chronic and recurrent frontal sinusitis and fronto ethmoidal mucocele, Dr. TA diagnose and investigate the patients with external frontal fistula and Dr. AS with Dr. TA did the extended endoscopic frontal sinus surgery. All authors have read and approved the manuscript. All Authors have contributed to the article.

\section{Funding}

There is no source of funding.

\section{Availability of data and materials}

The datasets analyses which were used during our current study and are available from the corresponding author on reasonable request.

\section{Declarations}

\section{Ethics approval and consent to participate}

The Ethics Committee at Al Azhar University Hospital approved this study, reference number is

ENT_33Med.Research_frontal,Draff.Endoscopic.Recurrent.Frontal

sinusitis_0000033, and written informed consent was taken from all patients.

\section{Competing interests}

There are no competing interests.

\section{Author details}

${ }^{1}$ Otorhinolaryngology Department., Faculty of Medicine, Al Azhar University., Cairo, Egypt. ${ }^{2}$ Otorhinolaryngology Department., Faculty of Medicine for Girls ,Al Azhar University, Cairo, Egypt.

Received: 4 February 2021 Accepted: 7 April 2021

Published online: 12 May 2021

\section{References}

1. Bachert C (2016) Innovative therapeutic targets in chronic sinusitis with nasal polyps. Braz J Otorhinolaryngol 82(3):251-252. https://doi.org/10.1016/ j.bjorl.2016.03.001

2. Stammberger H, Posawetz W (1990) Functional endoscopic sinus surgery. Concept, indications and results of the Messerklinger technique. Eur Arch Otorhinolaryngol 247(2):63-76. https://doi.org/10.1007/BF00183169

3. Fandiño CM, Macdonald KI, Lee J et al (2013) The use of postoperative topical corticosteroids in chronic rhinosinusitis with nasal polyps: a systematic review and meta-analysis. Am J Rhinol Allergy 27(5):e146-e157. https://doi.org/10.2500/aira.2013.27.3950

4. Shen PH, Weitzel EK, Lai JT, Wormald PJ, Lin CH (2011) Retrospective study of full house functional endoscopic sinus surgery for revision endoscopic sinus surgery. Int Forum Allergy Rhinol 1(6):498-503. https://doi.org/10.1 002/alr.20081

5. Sindwani R (2008) Frontal sinus osteomas: the window of endonasal endoscopic approach. Yearbook Otolaryngol Head Neck Surg 2008:252-253. https://doi.org/10.1016/S1041-892X(08)79124-8

6. Christmas DA, Krouse JH (1996) Powered instrumentation in dissection of the frontal recess. Ear Nose Throat J 75(6):359-366. https://doi.org/10.1177/ 014556139607500609

7. Samaha M, Cosenza MJ, Metson R (2003) Endoscopic frontal sinus drillout in 100 patients. Otolaryngol Head Neck Surg 129:854-858

8. Beule AG, Steinmeier E, Kaftan H, Biebler KE, Gopferich A, Wolf E, Hosemann W (2009) Effects of a dexamethasonereleasing stent on osteoneogenesis in a rabbit model. Am J Rhinol Allergy 23(4):433-436. https://doi.org/10.2500/a jra.2009.23.3331

9. Patel V, Choby G, Shih LC et al (2018) Equivalence in outcomes between Draf IIB vs Draf III frontal sinusotomy for refractory chronic frontal rhinosinusitis. Int Forum Allergy Rhino 8(1):25-31. https://doi.org/10.1002/a Ir.22032

10. Orlandi RR, Kennedy DW (2001) Revision endoscopic frontal sinus surgery. OtolaryngolClin North Am 34(1):77-90. https://doi.org/10.1016/S00306665(05)70296-6

11. Nguyen QA, Leopold DA (1997) Current concepts in the surgical management of chronic frontal sinusitis. OtolaryngolClin North Am 30(3): 355-370. https://doi.org/10.1016/S0030-6665(20)30215-2

12. Schlosser RJ, Zachmann G, Harrison S et al (2002) The endoscopic modified Lothrop: long-term follow-up on 44 patients. Am J Rhinol 16(2):103-108. https://doi.org/10.1177/194589240201600206

\section{Publisher's Note}

Springer Nature remains neutral with regard to jurisdictional claims in published maps and institutional affiliations.

\section{Consent for publication}

Written informed consent was taken from all participants for publication as regard to their details, images, and their videos. 